EPJ Web of Conferences 29, 00038 (2012)

DOI: $10.1051 /$ epjconf/20122900038

(C) Owned by the authors, published by EDP Sciences, 2012

\title{
Synthesis of PZT powder by conventional method at various conditions
}

\author{
Z. Necira ${ }^{a}$, A. Boutarfaia, M. Abba and N. Abdessalem \\ Laboratory of Applied Chemistry, Department of Science Matter, University of Biskra, B.P.145 R. \\ Biskra (07000) Algeria.
}

\begin{abstract}
In this work, the formation of $\mathrm{Pb}\left(\mathrm{Zr}_{1-\mathrm{x}} \mathrm{Ti}_{\mathrm{x}}\right) \mathrm{O}_{3}$ solid solutions with composition near the morphotropic phase boundary (MPB) using the conventional ceramic method have been studied by changing the thermal conditions such as temperature ramp rate and isothermal times during the calcination treatment performed between 700 and $900{ }^{\circ} \mathrm{C}$. The perovskite phase formation and morphology of undoped $\mathrm{Pb}\left(\mathrm{Zr}_{0.52} \mathrm{Ti}_{0.48}\right) \mathrm{O}_{3}$ (abbreviated PZT) and doped new material $\mathrm{Pb}_{0.98} \mathrm{Gd}_{0.02}\left[\left(\mathrm{Zr}_{0.52} \mathrm{Ti}_{0.48}\right)_{0.98}\right.$ $\left(\mathrm{Mg}_{1 / 3} \mathrm{Nb}_{2 / 3}\right)_{0.01}\left(\mathrm{Ni}_{1 / 3} \mathrm{Sb}_{2 / 3}\right)_{0.01} \mathrm{O}_{3}$ (abbreviated PZT-PGMNNS) specimens have been examined by powder X-ray diffraction (XRD), scanning electron microscopy (SEM) and Fourier Transform Infrared (FTIR) while the thermal evolution of the initial precursor was followed by TG-DTA. So the results of these studies have been discussed. Keywords: $\mathrm{Pb}\left(\mathrm{Zr}_{1-\mathrm{x}} \mathrm{Ti}_{\mathrm{x}}\right) \mathrm{O}_{3}$; Morphotropic phase boundary; Calcination treatment; Perovskite phase.
\end{abstract}

\section{Introduction}

The solid solution of $\mathrm{Pb}\left(\mathrm{Zr}_{1-\mathrm{x}}, \mathrm{Ti}_{\mathrm{x}}\right) \mathrm{O}_{3}$, known as lead zirconate titanate (PZT), is one of the most studied ferroelectric materials in the past 40 years, especially because of its excellent dielectric, ferroelectric and piezoelectric properties [1-5]. The highest piezoelectric coefficients of PZT are found for compositions near the morphotropic phase boundary (MPB) between the tetragonal and rhombohedral regions of the composition-temperature phase diagram [6,7]. Generally, the material of PZT is fabricated by a solid-state reaction among $\mathrm{PbO}, \mathrm{TiO}_{2}$ and $\mathrm{ZrO}_{2}$ (ordinary dry method) by which the sequences of this reaction are today well known and several studies describe them very well [8-14]. Most authors agree that the solid state reaction usually begins by the formation of a highly tetragonal lead titanate solid solution, which the remaining $\mathrm{PbO}$ and $\mathrm{ZrO}_{2}$ react to form $\mathrm{Pb}\left(\mathrm{Zr}_{1-\mathrm{x}} \mathrm{Ti}_{\mathrm{X}}\right) \mathrm{O}_{3}$. One version of the course of reaction is shown in Fig.1. [15], which shows the different phases present depending on the temperature.

\footnotetext{
a e-mail : necirafaiza@yahoo.fr
} 


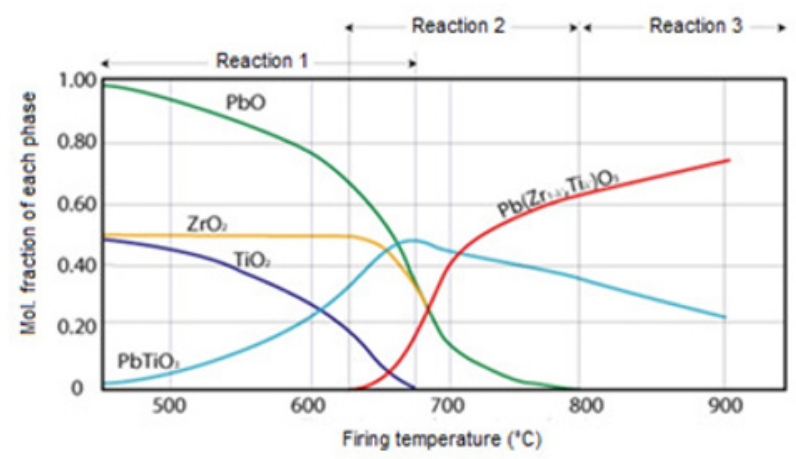

Fig1. Phases in the system $\mathrm{PbO}: \mathrm{TiO}_{2}-\mathrm{PbO}: \mathrm{ZrO}_{2}$ as a function of firing temperature.

The transformations undergone by the initial mixture oxides during its heat treatment can be simple or complex depending on the nature and the reactivity of the starting oxides (purity, structure, grain size, etc...) $[16,17]$ which choice of the composition of the reaction mixture, the addition of various dopants [18] and the thermal conditions (heating/cooling rates and isothermal times) [19] that seem to have a great effect on the progress of the reaction including the formation of the desired final phase (PZT).

To define the thermal conditions that govern the reaction mechanism, it is necessary to use several techniques to determine unambiguously the final product formed. Therefore, the study is attempted to describe and to explain the thermal conditions which govern the phase formation of pure and doped $\mathrm{Pb}\left(\mathrm{Zr}_{1-\mathrm{x}} \mathrm{Ti}_{\mathrm{x}}\right) \mathrm{O}_{3}$ solutions, prepared by a conventional mixed-oxide method at various processing conditions like; calcination temperature; temperature ramp rates and isothermal times using different analysis techniques such as X-ray diffraction and thermal analysis techniques that are very often complete each other.

\section{Experimental procedure}

The compositions that used in this study are $\mathrm{Pb}\left(\mathrm{Zr}_{0.52} \mathrm{Ti}_{0.48}\right) \mathrm{O}_{3}$ (undoped PZT) and $\mathrm{Pb}_{0.98} \mathrm{Gd}_{0.02}\left[\left(\mathrm{Zr}_{0.52} \mathrm{Ti}_{0.48}\right)_{0.98}\left(\mathrm{Mg}_{1 / 3} \mathrm{Nb}_{2 / 3}\right)_{0.01}\left(\mathrm{Ni}_{1 / 3} \mathrm{Sb}_{2 / 3}\right)_{0.01}\right]_{3}$ (doped PZT-PGMNNS) close to the morphotropic phase boundary (MPB). These systems were prepared by the conventional ceramic method. The starting raw materials in oxide form of high purity used were $\mathrm{PbO}$ (massicot, $99.0 \%$ purity, Biochem), $\mathrm{ZrO} 2$ (baddeleyute, 99.0\% purity, Biochem ), $\mathrm{TiO} 2$ (60,2\% rutile and 39,8\% anatase, $99.0 \%$ purity, Biochem), $\mathrm{Gd}_{2} \mathrm{O}_{3}(99.99 \%$ purity, Alfa Aesar) $\mathrm{MgO}$ (99.6\% purity, Alfa Aesar ), $\mathrm{Nb}_{2} \mathrm{O}_{5}\left(99.95 \%\right.$ purity, Alfa Aesar) $\mathrm{NiO}\left(99.6 \%\right.$ purity, Alfa Aesar ) and $\mathrm{Sb}_{2} \mathrm{O}_{3}(>99.0 \%$ purity, Biochem).

For the preparation of PZT and PZT-PGMNNS precursors, the starting powders were weighted in the required stoichiometric ratio and then mixed in acetone medium for $24 \mathrm{~h}$ through a magnetic stirrer to achieve homogenization. After drying process, the mixed powders were crushed for $6 \mathrm{~h}$ in a mortar with a pestle. To ease the reactions in solid, the powders were pressed into13 $\mathrm{mm}$ in diameter and $2 \mathrm{~mm}$ thick pellets under uni-axial pressure of $750 \mathrm{MPa}$. The resultant specimens were calcined on alumina plates at temperatures between 700 and $900{ }^{\circ} \mathrm{C}$. The chosen conditions of temperature ramp rates and duration (isothermal time) were varied from 2 to $10^{\circ} \mathrm{C} \mathrm{min}^{-1}$ and from 2 to $6 \mathrm{~h}$, respectively.

After calcinations, the fired product was analyzed by X-ray diffraction (XRD: BRUKER-AXE, D8) using $\mathrm{CuK} \alpha$ radiation. The results, i.e. peak positions; were compared with the information from the JCPDS database to identify the presence of the perovskite structure and phases present. The general morphology of the calcined specimens were observed by scanning electron microscopy (SEM: JEOL JSM -6390LV) at room temperature. 
Complementary analysis which confirm the formation temperature of the perovskite phase, such as thermal analyses (TG/DTA: L70/2171 Thyristor-Power Supply) from 25 to $900^{\circ} \mathrm{C}$ at a heating rate of $10^{\circ} \mathrm{C} \mathrm{min}^{-1}$ and infrared analysis (FTIR: FTR-8400S SHIMADZU) in the 4000-400 rang using the $\mathrm{KBr}$ pellet technique (about $1 \mathrm{mg}$ of sample and $200 \mathrm{mg}$ of $\mathrm{KBr}$ were used for the preparation of the pellets) were performed.

\section{Results and discussion}

The thermal analyses (TG/DTA) provides additional information on the synthesis and the thermal conditions of the phase formation. Fig. 1 displays the TG/DTA curves performed over the undoped and doped powder mixture compositions selected for this study. These results confirm our good choice of the temperature range (between 700 and $900{ }^{\circ} \mathrm{C}$ ) for samples calcinations. From these figures we deduce observe that the temperature of the perovskite phase formation is estimated between 700 and $750{ }^{\circ} \mathrm{C}$, in correlation with an endothermic peak centered at ca. $730{ }^{\circ} \mathrm{C}$ (fig. 1(a)) which corresponds mainly to an oxygen loss resulting from the formation of the final perovskite phase for the undoped powder. While it is estimated at a higher temperature $\left(750\right.$ to $850{ }^{\circ} \mathrm{C}$ (fig. 1(b)) in correlation with an endothermic peak centered at ca. $800{ }^{\circ} \mathrm{C}$ ) for the doped powder which indicates that doping affects the temperature of the phase formation. These results are in agreement with FTIR and XRD results discussed below.
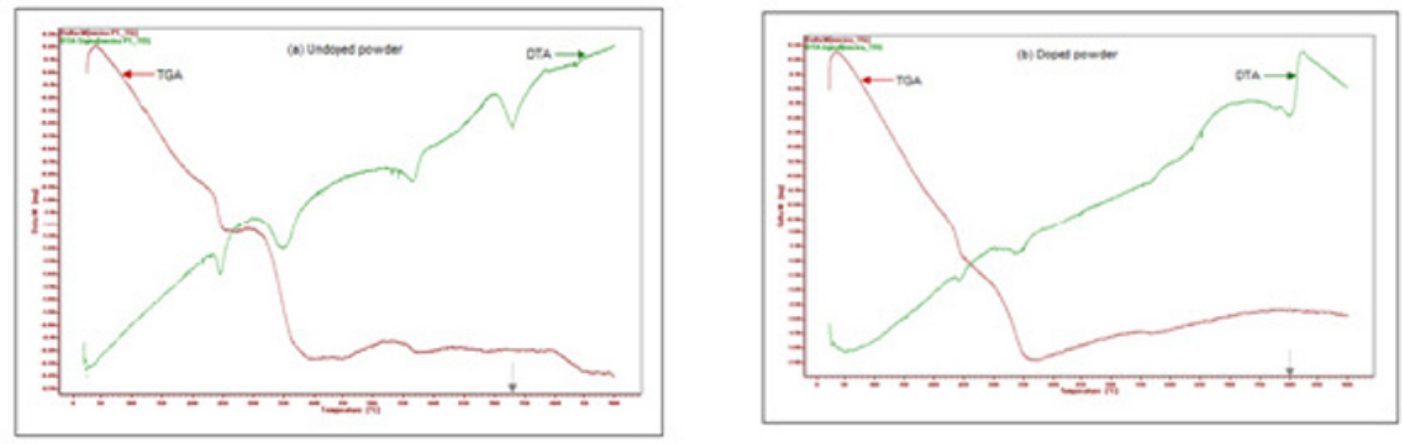

Fig. 1: TG/DTA curves for the powder mixture compositions: (a) undoped powder, (b) doped powder.

With FTIR analysis, it was possible to track the formation, as a function of calcination temperatures, of PZT's $\mathrm{ABO}_{3}$ structure. Fig. 2 presents the IR spectra, in the zone between 4000 and $400 \mathrm{~cm}^{-1}$ for all phases of undoped PZT and doped PZT-PGMNNS samples. In Figs. 2a and $2 \mathrm{~b}$, the most important band, that extends from 800 to $400 \mathrm{~cm}^{-1}$, of the perovskites structure, is observed with a maximum absorption at $\sim 600 \mathrm{~cm}^{-1}$, which is the characteristic band of oxides with perovskite-type structure [20,21]. This bands exhibit a significant increase for the samples calcined at a higher temperature $\left(800\right.$ and $\left.900{ }^{\circ} \mathrm{C}\right)$. Noting that a small band at about $\sim 1600 \mathrm{~cm}^{-1}$ which is probably typical of the presence of some water in the $\mathrm{KBr}$ employed to dilute the samples into the pellets and chemisorbed from the atmosphere onto the samples is also observed in some of the spectra.

With DRX analysis it was possible to ensure of the phase purity and identify the crystalline phases of the calcined powders at different thermal conditions. Fig. 3 shows the XRD patterns of undoped PZT and doped PZT-PGMNNS powders at various calcination temperatures $(750,800$ and $\left.900{ }^{\circ} \mathrm{C}\right)$, temperature ramp rates $\left(2\right.$ and $\left.10{ }^{\circ} \mathrm{C} / \mathrm{min}\right)$ and periods of time $(2$ and $6 \mathrm{~h})$. Similar trends were also observed for PZT produced by using other thermal conditions [22,23]. 

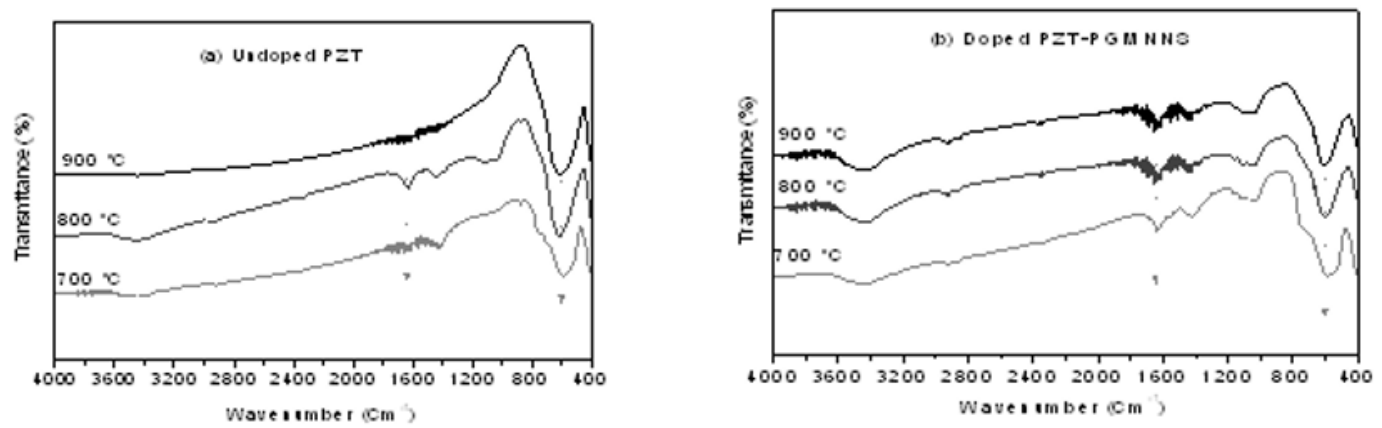

Fig.2: FTIR spectra of the samples calcined at the indicated temperatures using a temperature ramp rate of $2{ }^{\circ} \mathrm{C} / \mathrm{min}$ for $2 \mathrm{~h}$ : (a) undoped PZT (b) doped PZT-PGMNNS
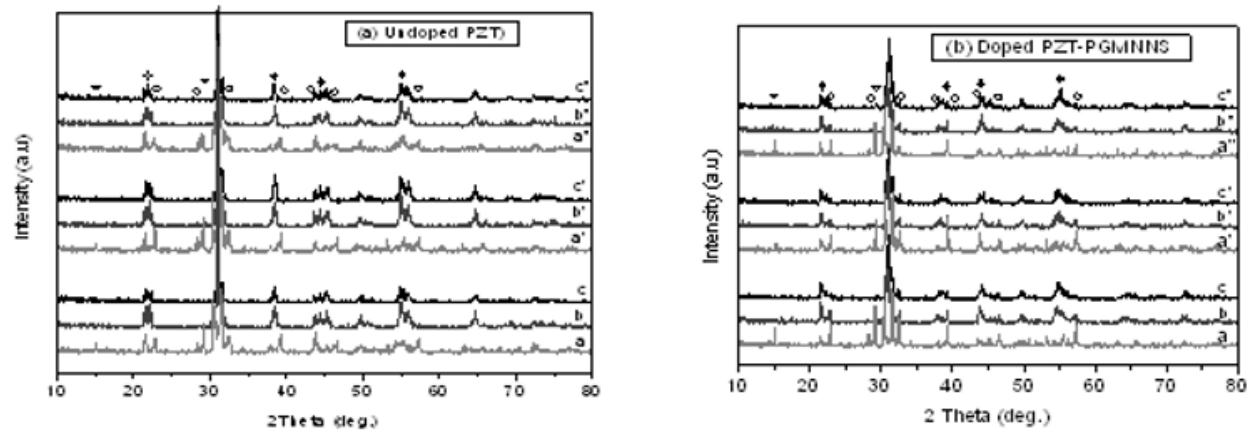

Fig. 3. XRD patterns of powders calcinted at different temperatures and for different isothermal times and temperature ramp rats for undoped PZT and doped PZT-PGMNNS : a,b,c) $10^{\circ} \mathrm{C} / \mathrm{min}$ until $700{ }^{\circ} \mathrm{C}, 800{ }^{\circ} \mathrm{C}$, $900^{\circ} \mathrm{C}$ for $2 \mathrm{~h}, \mathrm{a}^{\prime}, \mathrm{b}^{\prime}, \mathrm{c}$ ' and a', b', c',') $2^{\circ} \mathrm{C} / \mathrm{min}$ until $700{ }^{\circ} \mathrm{C}, 800^{\circ} \mathrm{C}, 900^{\circ} \mathrm{C}$ for $2 \mathrm{~h}$ and $6 \mathrm{~h}$ respectively. In this figure $(\mathrm{P})$ stands for $\mathrm{PbO}(\nabla),(\mathrm{PT})$ for $\mathrm{PbTiO} 3(\mathrm{O}),(\mathrm{PZ})$ for $\mathrm{PbZrO} 3(\diamond)$ for $\mathrm{PZT}\left(\iota^{\circ}\right)$.

From these figures it was found that PZT perovskite phase with co-existence of both tetragonal and rhombohedral phases matching with the JCPDS file no. 33-0784 and 73-2022, respectively and without any trace of pyrocholre phase normally forms was observed in all the samples. In the XRD patterns of the undoped and doped powders that were reacted at $700{ }^{\circ} \mathrm{C}$ using a ramp rate of 2 and $10{ }^{\circ} \mathrm{C} / \mathrm{min}$ for 2 and $6 \mathrm{~h}$ (Fig. 3a, 3b) additional peaks at approximately $15^{\circ}, 29^{\circ} 2 \theta$ and were detected. These can be attributed to the presence of unreacted PbO. Peaks of PT (JCPDS no. 060452), and PZ (JCPDS no. 035-0739 ) were also observed in the XRD patterns which is believed to the originate from the uncompleted reaction during powder calcination at these thermal conditions. When the reaction temperature was increased to $800{ }^{\circ} \mathrm{C}$ with changing the heating profile ( 2 to $6 \mathrm{~h}$ and 10 to $2{ }^{\circ} \mathrm{C} / \mathrm{min}$ ), no PT and PZ peaks were observed in the XRD patterns. This means that a reaction had occurred. All the samples calcined at $900^{\circ} \mathrm{C}$ exhibit almost the same XRD spectrum. The stoichiometric composition diffraction patterns calcination between 700 and $900{ }^{\circ} \mathrm{C}$ using a ramp rate of $2{ }^{\circ} \mathrm{C} / \mathrm{min}$ for $6 \mathrm{~h}$, which are considering as optimal thermal parameters for this study is shown in Fig. 4 and compared with doped simple composition. It is possible to observe that the number of $\mathrm{PbO}$ peaks is less compared with doped sample calcined under the same conditions. This result could well indicate that the perovskite phase formation is not complete for doped compositions. When the calcination temperature is increased, the reaction is observed to be almost complete and the perovskite structure is dominated in XRD for all compositions. Notice that a heating profile also influences the final particle size and size distribution of phase formation. 


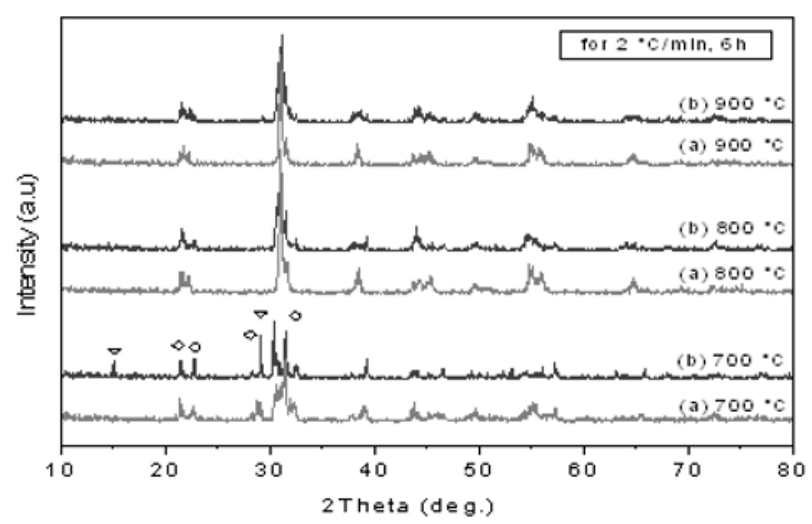

Fig. 4. XRD patterns of PZT and PZT-PGMNNS powders at different temperatures with a temperature ramp rate of $2{ }^{\circ} \mathrm{C} / \mathrm{min}$ for $6 \mathrm{~h}$.

In Fig. 5, the particle morphology of the powders is compared. It can be noted that the increasing of reaction temperature (top to bottom) or time (left to right) led to increase in the particle size. This is more evident for powders synthesized with isothermal time of $6 \mathrm{~h}$.
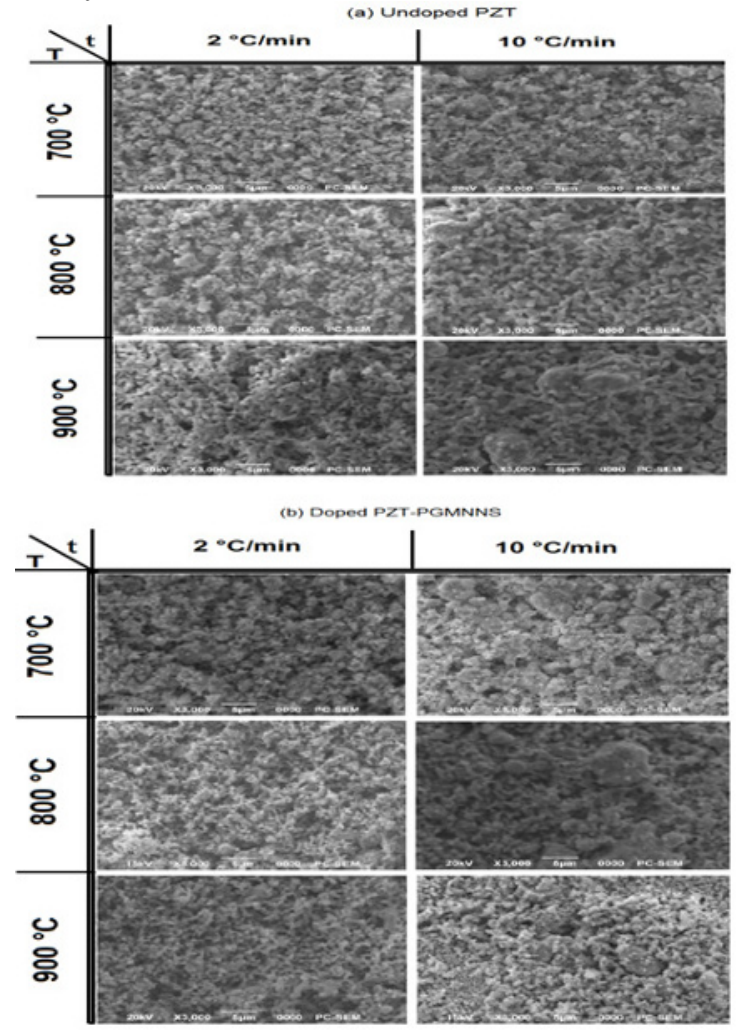

Fig.5: SEM micrographs of powders calcinted at different temperatures and for 2 and $6 \mathrm{~h}$ of isothermal times (a) undoped PZT (b) doped PZT-PGMNNS

The shape gradually became more regular with the increasing of isothermal time (left to right). Both the phenomena were also observed at lower heating ramp rates (Figs. 6(a), 6(b)). At the lowest processing temperature and time $\left(700{ }^{\circ} \mathrm{C}, 2 \mathrm{~h}\right)$ the synthesized PZT powder had a distinctive spherical shape (Fig. 6a) which became less pronounced with the increasing process parameters the final 
particle size and size distribution of it was instead observed that a change in the particle shape occurred with particles becoming more regular with decreasing ramp rates (at constant isothermal time and temperature).
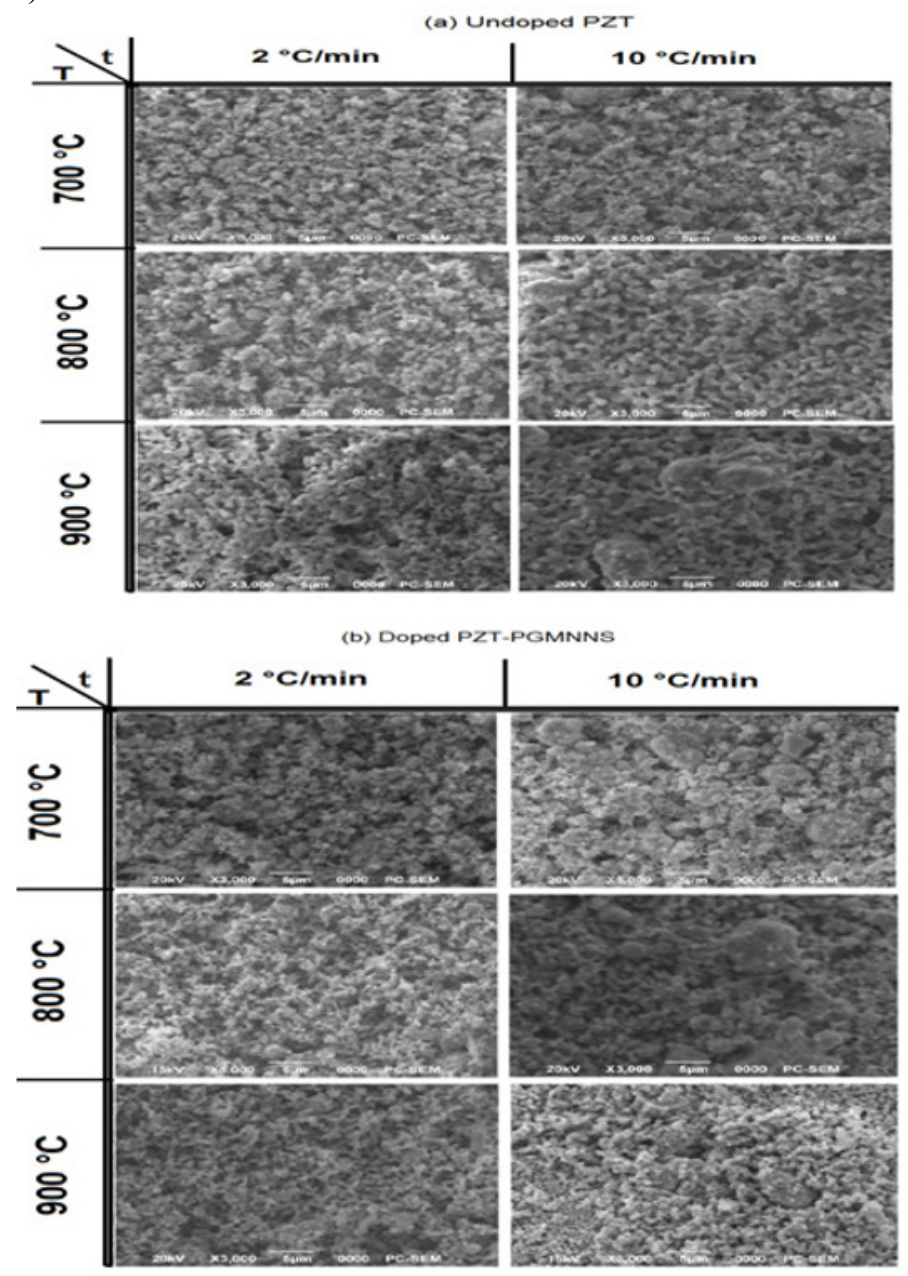

Fig.6: SEM micrographs of powders calcinted at different temperatures and with temperature ramp rats of 2 and $10{ }^{\circ} \mathrm{C} / \mathrm{min}$ for: (a) undoped PZT (b) doped PZT-PGMNNS.

Moreover an increment in the heating rate led to a larger particle size distribution with the presence of big particles in the final PZT powder. This correlates with the observed results by others [22].

\section{Conclusion}

The effect of thermal process parameters such as calcination temperature, reaction time and temperature ramp rate on the perovskite phase formation and general particle size morphology of undoped and doped PZTcompositions was investigated by solid-state route. Thus, the results obtained in this study allowed us to suggest a standardized thermal profile that can be used to synthesize new materials using the same state route. For samples calcined at $700{ }^{\circ} \mathrm{C}$ whith higher temperature ramp rate $\left(10{ }^{\circ} \mathrm{C} / \mathrm{min}\right)$, the reaction between the starting materials was not complete. Residual $\mathrm{PbO}$ and intermediate solide solutions (PT and PZ) were found within the product. A single perovskite phase type was observed as calcination temperature increased at $800{ }^{\circ} \mathrm{C}$. At temperature 
higher $900{ }^{\circ} \mathrm{C}$ there is no notable change which allows us to consider that $800{ }^{\circ} \mathrm{C}$ as the optimum temperature of calcination samples using the ramp rate of $2^{\circ} / \mathrm{min}$ and $6 \mathrm{~h}$ of during time. The particles obtained at $700{ }^{\circ} \mathrm{C}$ and at fast heating rates were less spherical than the same powder treated at higher temperatures for the same isothermal time. At high temperatures and long reaction times an excessive particle growth was observed. The regular particles were obtained by heating the raw materials at $800 \circ \mathrm{C}$ for $2 \mathrm{~h}$ using a slow temperature ramp rate $\left(2{ }^{\circ} \mathrm{C} / \mathrm{min}^{-1}\right)$.

\section{References}

1. B. Jaffe, W. R. Cook, H. Jaffe, Piezoelectric Ceramics, AcademicPress, New York, (1971).

2. B. Jaffe, W. Cook and H. Jaffe, Piezoelectric ceramics (New York: Academic) p 117, (1971).

3. Matsuo Y., Sasaki h., Formation of lead zirconate-lead titanate solid solutions, J. Am. Ceram. Soc., 48 289-291, (1965).

4. E. Quandt, A. Ludwig, Sens. Actuators 81, 275. (2000).

5. R. Zuo, L. Li, X. Hu, Z. Gui, Mater. Lett. 54, 185. (2002).

6. K. Nagata, J. Thongrueng, J. Korea Appl. Soc. 32, S1278. (1998).

7. A. Pinczuk, Solid State Commun. 12, 1035. (1973).

8. A. Boutarfaia, S.E. Bouaoud, Ceram. Int. 22, 281-286. (1996).

9. L'. Medveck'y, M. Kmecov', K. Saksl, Journal of the European Ceramic Society 27, 2031-2037. (2007).

10. T. R. Shrout, P. Pate, S. Kim and G. S. LEE, J. Amer. Ceram. Soc. 73(7) 1862. (1990).

11. C. A. Randall, N. KIM, J. P. Kucera, W. W. Cao and T. R. Shrout, ibid. 81(3) 677. (1998).

12. T. Yamamoto, Am. Ceram. Soc. Bull. 71(6) 978. (1992).

13. Jona F and Shirane G 1993 Ferroelectric Crystals (New York: Dover) hys. Res., B 98 (1995).

14. N. Chakrabarti and H. S. MAITI, Mater. Lett. 30 (1997).

15. Matsua, Y. and Luff, D. Tans. Br. Ceram. Soc. 61, 85-93. (1962).

16. Venkataramani S., Biggers J. V., Bull. Am. Ceram. Soc., 59, 462-466. (1980).

17. B.V. Hiremath, Angus i. Kingon, and James V. Biggers., Materials Research Laboratory. Pennsylvania 16802, p790-792, (1983).

18. A.I.Kingon, PJ. Terblanche and J.B. Clark. Effect., Ceramic International. Vol.8, $\mathrm{n}^{\circ} 3$,(1982).

19. B.V. Hiremath, I. Angus Kingon, and V. James V. Biggers, Materials Research Laboratory. Pennsylvania 16802, p790-792, (1983).

20. J. T. Last, Phys. Rev. 105, 1740, (1957).

21. Guarany1 C. A., L. H. Z. Pelaio1, E. B. Aráujo1,3,4, K Yukimitu1,4, J C SMoraes1,4 and J A Eiras2 'Infrared studies of the monoclinic-tetragonal phase transition in $\mathrm{Pb}(\mathrm{Zr}, \mathrm{Ti}) \mathrm{O} 3$ ceramics' J. Phys.: Condens. Matter 15, 4851-4857, (2003).

22. A. I. Kingon, PJ. Terblanche and J. B. Clark, Ceram Intrn. 8, n.3 (1982) Francesca Bortolani, Robert A. Dorey, JECS-7866; No. of Pages 7(2010). 